\title{
Finite Difference Methods for solving hydraulic behaviour equations of the surge tanks
}

\author{
Ramtin Moeini ${ }^{1}$ \\ ${ }^{1}$ University of Isfahan
}

July 30,2020

\begin{abstract}
In this paper, the hydraulic behaviour of different types of surge tanks is modelled and solved using four different types of the Finite Difference Method. Water hammer is one of the most important phenomena in hydraulic systems. Surge tank is one of the most important devices used to reduce damages of this phenomenon. Here, the equations of hydraulic behaviour of simple, orifice and closed surge tank are derived at with or without friction condition in both gradually and suddenly valve closing. The Explicit Euler, Implicit Euler, Predictor-Corrector Euler and forth order Rung-Kutta methods are used to solve these hydraulic equations and the results are presented and compared. Comparison of the results show that the value ranges of fluid level oscillation at with friction condition is smaller than those at without friction condition using all proposed methods at both suddenly and gradually valve closing. Furthermore, for all types of surge tanks' at all different considering conditions, the smallest ranges of fluid level oscillation are obtained when the Implicit Euler is used. In addition, by using Implicit Euler method the fluid level oscillation converges faster than the other methods. Moreover, fluid level oscillations are unsteady for simple and closed surge tank at without friction condition in both gradually and suddenly valve closing using Explicit Euler and Predictor-Corrector Euler. However, other obtained fluid level oscillations are steady.
\end{abstract}

\section{Hosted file}

FDM for solving hydraulic behavior equations of surge tanks.doc available at https: //authorea.com/users/347571/articles/473215-finite-difference-methods-for-solvinghydraulic-behaviour-equations-of-the-surge-tanks 